\title{
ESTUDO DA CAPACIDADE DE COMPLEXAÇÃO E SUA RELAÇÃO COM ALGUMAS VARIÁVEIS AMBIENTAIS EM CINCO REPRESAS DO RIO TIETÊ/BRASIL
}

\author{
Elisangela C. L. Borges*, Antonio Aparecido Mozeto e Eduardo F. Almeida Neves ${ }^{\text {t }}$ \\ Departamento de Química, Universidade Federal de São Carlos, CP 676, 13560-970 São Carlos - SP, Brasil \\ Waldomiro Borges Neto \\ Departamento de Química Analítica, Universidade Estadual de Campinas, CP 6154, 13084-971 Campinas - SP, Brasil \\ José Mauro Bezerra \\ Unidade Universitária de Ciências Exatas e Tecnológicas, Universidade Estadual de Goiás, CP 459, 75133-050 \\ Anápolis - GO, Brasil
}

Recebi em 26/1/06; aceito em 23/3/07; publicado na web em 30/7/07

\begin{abstract}
STUDY OF COMPLEXATION CAPACITY AND ITS RELATIONSHIP WITH SOME ENVIRONMENTAL VARIABLES IN FIVE RESERVOIRS OF THE TIETÊ RIVER SYSTEM. The copper and cadmium complexation properties in natural sediment suspensions of reservoirs of the Tietê River were studied using the solid membrane copper and cadmium ion-selective electrodes. The complexation and the average conditional stability constants were determined under equilibrium conditions at $\mathrm{pH}=6.00 \pm 0.05$ in a medium of $1.0 \mathrm{~mol} \mathrm{~L}^{-1}$ sodium nitrate, using the Scatchard method. The copper and cadmium electrodes presented Nernstian behavior from $1 \times 10^{-6}$ to $1 \times 10^{-3} \mathrm{~mol} \mathrm{~L}^{-1}$ of total metal concentration. Scatchard graphs suggest two classes of binding sites for both metals. A multivariate study was done to correlate the reservoirs and the variables: complexation properties, size, total organic carbon, volatile acid sulfide, $\mathrm{E}_{\mathrm{H}}$ and $\mathrm{pH}$.
\end{abstract}

Keywords: ion-selective electrodes; complexation and adsorption capacities; Chemometrics.

\section{INTRODUÇÃO}

A construção de reservatórios é um dos principais fatores modificadores dos ecossistemas naturais ${ }^{1}$, cujo maior impacto é, algumas vezes, o rápido processo de eutrofização a que estão sujeitos, principalmente nos primeiros anos de construção, como reflexo da inundação de grandes áreas verdes adjacentes ${ }^{2}$.

Nos reservatórios do rio Tietê, a intensificação deste processo está associada à sobrecarga de nutrientes que recebem a partir dos despejos domésticos e industriais, bem como da água de escoamento de áreas agrícolas, dominado principalmente por plantações de cana-de-açúcar ${ }^{3-5}$, o que se constitui em um agravante à degradação destes ecossistemas.

Além das altas concentrações de nutrientes $(\mathrm{C}, \mathrm{N}$ e $\mathrm{P})$ em tais ambientes. é comum a presença de xenobióticos como elementos metálicos e não metálicos (especialmente de $\mathrm{Cd}, \mathrm{Cr}, \mathrm{Pb}, \mathrm{Be}, \mathrm{As}, \mathrm{Hg}$ ) e de substâncias orgânicas voláteis e semivoláteis (tais como vários compostos organo-clorados e fenóxi-ácidos) em baixos níveis de detecção e de reconhecida toxicidade, sendo que muitos destes têm propriedades carcinogênicas, mutagênicas e teratogênicas ${ }^{6}$.

Os metais associados aos materiais das diversas fontes naturais (lixiviação de solos e intemperização de rochas) e antropogênicas ao serem descarregados nos ambientes aquáticos sofrem uma partição entre a água e os particulados suspensos, sendo que parte desta carga é metabolizada pela biota (animal e vegetal) e parte terá como destino final os sedimentos de fundo desses ambientes através da combinação dos processos de floculação e sedimentação ${ }^{1,7}$. O mecanismo de partição é também ativo no compartimento sedimento entre a fase sólida (partículas orgânicas e inorgânicas) e a fase solúvel (água intersticial), onde se encontram íons metálicos, nutrientes e outras

*e-mail: elisangelaborges@inhumas.cefetgo.br

tIn Memoriam substâncias dissolvidas ${ }^{8-11}$. Grande parte dos materiais depositados nos interstícios do sedimento pode se redissolver por um fluxo difusivo e ser transportado para camadas superficiais do meio aquático. Assim, na interface sedimento-água, particularmente na zona oxidativa, podem ocorrer processos de mineralização através de reações catalisadas por microorganismos, variando a especiação e mobilidade de xenobióticos ${ }^{12-14}$.

Pelo fato dos sedimentos agirem como um reservatório de contaminantes para o ambiente e para os organismos que vivem sob ou estão em contato direto com este compartimento, os sedimentos contaminados representam um grande risco para a biota. Uma avaliação eficaz deste risco requer o entendimento das relações entre concentrações de contaminantes nos sedimentos e ocorrência de efeitos adversos à biota ${ }^{7,11}$.

A capacidade de complexação é um dos parâmetros fundamentais para se estimar esta relação de qualidade, prevendo a partir dela o quanto um compartimento ambiental pode ser considerado como um sumidouro através da retenção de metais, isto é, a saturação. Para tanto, utilizam-se técnicas eletroanalíticas ${ }^{9,14-22}$, espectroscópicas ${ }^{23,24}$ ou titulação com EDTA $^{25}$ para a obtenção gráfica e determinação de valores que estimem esta capacidade.

A principal aplicação da potenciometria no estudo dos sedimentos naturais tem sido na investigação da concentração dos ligantes presentes $(\mathrm{Cc}$ ou L) como também a sua estabilidade através da constante de formação condicional $\left(\mathrm{K}^{\prime}\right)^{14,22}$. A possibilidade de se estabelecer uma correlação entre os resultados desta determinação por potenciometria e a toxicidade de certos xenobióticos, sob condições particulares, tem permitindo uma abordagem mais ampla à determinação potenciométrica.

Dentre os métodos gráficos mais discutidos na literatura, que avaliam os sistemas aquáticos e determinam os valores da concentração do ligante e da constante de formação condicional para os complexos formados entre os xenobióticos e diversos ligantes, está o desenvolvido 
por Scatchard ${ }^{14-17,21,26}$, cuja representação se dá pela relação [ML]/[M] em função de [ML], onde [ML] é a concentração de metal complexado e [M] é a concentração de metal livre, expressa em $\mathrm{mol} \mathrm{L}^{-1}$.

A grande quantidade de informação química que pode ser obtida em estudos ambientais remete à necessidade de se complementar a descrição estatística com uma análise simultânea de todas as amostras e variáveis.

Os métodos multivariados são ferramentas estatísticas que consideram a correlação de vários resultados analisados simultaneamente, permitindo a extração de uma quantidade maior de informações, muitas vezes impossível quando se analisa variável a variável ${ }^{27,28}$, podendo utilizar diferentes estratégias para se obter a informação desejada ${ }^{28}$, como a análise por componentes principais (PCA) e a análise por agrupamento hierárquico (HCA).

O método de análise por componentes principais (PCA) é um método classificatório destinado a produzir grupos ou conglomerados de objetos (amostras) semelhantes, segundo suas casracterísticas (variáveis ${ }^{29}$. A PCA é utilizada para projetar dados n-dimensionais em um espaço de baixa dimensão, normalmente duas ou três, através do cálculo de componentes principais obtidas fazendo-se combinações lineares das variáveis originais. PCA é um método exploratório porque auxilia na elaboração de hipóteses gerais a partir dos dados coletados, contrastando com estudos direcionados nos quais hipóteses prévias são testadas. É também capaz de separar a informação importante da redundante e aleatória. Em uma análise de componentes principais, o agrupamento das amostras define a estrutura dos dados através de gráficos de scores e loadings, cujos eixos são componentes principais (PCs) nos quais os dados são projetados. Os scores fornecem a composição das PCs em relação às amostras, enquanto os loadings fornecem essa mesma composição em relação às variáveis. Como as PCs são ortogonais, é possível examinar as relações entre amostras e variáveis através dos gráficos dos scores e dos loadings. $\mathrm{O}$ estudo conjunto de scores e loadings ainda permite estimar a influência de cada variável em cada amostra ${ }^{30}$.

A análise por agrupamento hierárquico (HCA) é um método de ordenação e tem por finalidade o estudo das correlações existentes entre as variáveis de um grupo de objetos, não impedindo também que sejam utilizadas para classificação ${ }^{29}$. Este método tem por finalidade verificar a semelhança entre as linhas (amostras) de uma matriz de dados (variáveis ambientais), calculando-se a distância no espaço n-dimensional (variáveis), na maioria das vezes, a distância Euclidiana, conforme Equação $1^{31}$

$d_{a b}=\sqrt{\sum_{i=1}^{m}\left(x_{a i}-x_{b i}\right)^{2}}$

O resultado é apresentado na forma gráfica, denominada dendograma, assemelhando-se a uma estrutura em forma de árvore, sendo que $d_{a b}$ corresponde à distância entre os pontos a e b, e $\mathrm{d}_{\text {máx }}$ representa a distância entre qualquer par de pontos (amostras), onde são informadas a similaridade, conforme Equação $2^{31}$.

$S_{a b}=1-\frac{d_{a b}}{d_{\operatorname{máx}}}$

Utilizam-se vários métodos para calcular a similaridade entre as amostras. No presente estudo foi empregado o método incremental definido pela Equação $3^{31}$

$d_{a b \Rightarrow c}=\frac{\left(\left(n_{a}+n_{c}\right) d_{a c}^{2}+\left(n_{b}+n_{c}\right) d_{b c}^{2}-n_{c} d_{a b}^{2}\right)^{/ 2}}{n_{a}+n_{b}+n_{c}}$

onde $n_{i}$ corresponde ao número de amostras no grupo $i$.
O objetivo deste trabalho foi comparar os sedimentos naturais do reservatório Billings e das usinas hidrelétricas Rasgão, Barra Bonita, Bariri e Promissão, representando o Alto, Médio e Baixo Tietê quanto à capacidade de complexação para cádmio e cobre, e correlacionar estes valores com granulometria, carbono orgânico total (TOC), sulfeto volatilizável por acidificação (SVA), pH e $\mathrm{E}_{\mathrm{H}}$ através de uma análise classificatória.

\section{PARTE EXPERIMENTAL}

\section{Área de estudo: amostragem e pontos amostrais}

A coleta dos sedimentos e água intersticial foi realizada em junho de 2000 no reservatório Billings (Alto Tietê) e em quatro usinas hidrelétricas do Rio Tietê: Rasgão (Alto Tietê), Barra Bonita (Tietê/Jacaré), Bariri (Tietê/Jacaré) e Promissão (Baixo Tietê). Os pontos de coleta das amostras foram obtidos por GPS a uma distância de 1-3 km da barragem ${ }^{32}$ (Figura 1). Estas regiões possuem diferentes contribuições antropogênicas, seja na agricultura diversificada (cana-de-açúcar, cítricos, cultivo misto com irrigação) ou na exploração de minérios e portos de areia, esgoto doméstico e industrial ${ }^{5,33,34}$.

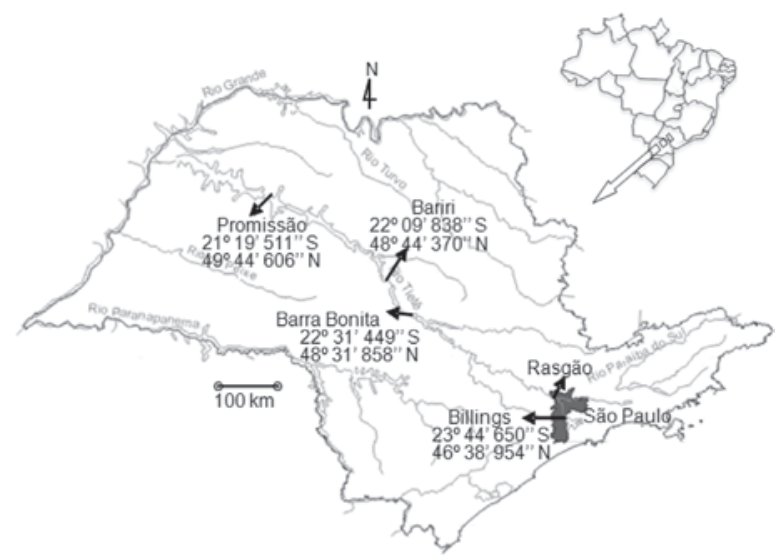

Figura 1. Mapa das coordenadas geográficas das represas e reservatórios do Rio Tietê $\hat{e}^{32}$. (Para a represa Rasgão não foi possível obter esta coordenada)

\section{Coleta das amostras}

Os ensaios químicos foram realizados em testemunhos curtos em um coletor cilíndrico do tipo gravidade ${ }^{35}$ lançado três vezes, gerando amostras compostas em intervalos de $5 \mathrm{~cm}$ cada. Estas amostras foram acondicionadas em sacos plásticos previamente limpos e avaliadas as variações de $\mathrm{pH}$ e $\mathrm{E}_{\mathrm{H}}$ in situ, utilizando um medidor multi-paramétrico Quanta (Hidrolab), em seguida, refrigeradas em gelo até a estocagem em um freezer.

As amostras para determinação granulométrica foram coletadas com uma draga de Birge-Ekman (realizada após a coleta dos testemunhos). Trata-se de uma draga construída em aço inox-316 com peso de aproximadamente $3,2 \mathrm{~kg}$ e uma área de amostragem de $15 \times 15 \mathrm{~cm}$ (área de base) e $20 \mathrm{~cm}$ de altura. Em cada ponto de amostragem a draga foi lançada 3 vezes.

\section{Granulometria}

A distribuição granulométrica foi feita segundo a norma ABNT NBR - 6502/95 ${ }^{36}$ descrita como uma combinação de sedimentação e peneiramento. 


\section{Concentração basal}

As concentrações de cádmio e cobre basais nos sedimentos foram determinadas por espectrometria de absorção atômica por chama (Intralab AA 12/1475 - Gemini) e por espectrometria de emissão ótica com plasma indutivamente acoplado (Jarrel - Ash, AtomComp 975) nas condições de operação dos respectivos fabricantes. O procedimento de decomposição foi executado segundo De Paula ${ }^{37}$ em amostra seca a $50{ }^{\circ} \mathrm{C}$.

A qualidade dos resultados analíticos foi acompanhada através do uso de "brancos analíticos" e da adoção de duplicatas de análises, distribuídas aleatoriamente. O branco analítico foi estimado através de seis determinações simultâneas às extrações das amostras.

\section{Extração de sulfeto volátil por acidificação}

O procedimento adotado para a extração de sulfeto volátil por acidificação foi desenvolvido por Allen et al. ${ }^{38} \mathrm{e}$ adaptado por Silvério $^{39}$. As quantificações foram realizadas em espectrofotômetro UV/V (Fento, modelo 432), via análise por injeção em fluxo, utilizando-se o método do azul de metileno descrito em Mozeto et al. ${ }^{40}$. Ensaios em branco foram realizados, sendo os valores desprezíveis quando comparados com os resultados das amostras.

\section{Carbono orgânico total e dissolvido}

A quantificação de carbono orgânico foi realizada em um analisador Shimadzu (TOC 5000), que utiliza a técnica de oxidação catalítica à alta temperatura. A determinação é feita com base na diferença entre a concentração de carbono total e a concentração de carbono inorgânico. As amostras de sedimento seco a $50{ }^{\circ} \mathrm{C}$ foram trituradas e homogeneizadas em almofariz.

\section{Capacidade de complexação e adsorção}

Em um módulo de filtração de polissulfonato (Sartorius) e membrana de acetato de celulose (Millipore 0,45 $\mathrm{mm}$ ), previamente deixados em repouso por $24 \mathrm{~h}$ em solução de $\mathrm{HNO}_{3} 10 \%(\mathrm{v} / \mathrm{v})^{22}$ realizou-se, primeiramente, a separação entre o sedimento e a água intersticial, obtendo-se assim a fração úmida (retida no filtro) e a fração dissolvida ou água intersticial (filtrado).

Os estudos de capacidade de complexação em sedimentos devem ser realizados com a amostra in natura para manter as suas características quantitativas e qualitativas, entretanto os cálculos são baseados em massa de sedimento seco. Dessa forma, a umidade de sedimento filtrado de cada ambiente (Tabela 1) foi determinada, previamente, para se saber o quanto de sedimento úmido devia ser utilizado para se obter uma relação de $300 \mathrm{mg}$ do sedimento seco para 50,0 mL de solução aquosa tamponada (pH 6,00 \pm 0,05 com PIPES 7,5 x $10^{-3} \mathrm{~mol} \mathrm{~L}^{-1}$ - piperazina N-N'ácido 2etanosulfônico, sal dissódico - Sigma, $\mathrm{pKa}=6,80$ ) com adição de pequenos volumes de $\mathrm{HNO}_{3}$ ou $\mathrm{NaOH}\left(1 ; 0,1\right.$ e $0,01 \mathrm{~mol} \mathrm{~L}^{-1}$, Synth) para controlar o $\mathrm{pH}^{22}$ e força iônica ajustada $\left(1,0 \mathrm{~mol} \mathrm{~L}^{-1} \mathrm{NaNO}_{3}\right.$, Merck), enquanto que na fração dissolvida adicionaram-se massas adequadas de PIPES e de $\mathrm{NaNO}_{3}$ para se obter as mesmas condições acima e ajustou-se o volume com porções líquidas deste filtrado. Para prevenir a aglutinação do sedimento e facilitar a dispersão adicionou-se $1,00 \mathrm{~mL}$ de solução Triton X-100 (0,5 mL Triton: $1000 \mathrm{~mL}$ água deionizada ${ }^{41}$ ), da Aldrich. Após $30 \mathrm{~min}$ sob agitação $(150 \mathrm{rpm})$ cada sistema foi deixado em repouso por $24 \mathrm{~h}$.

Todas as titulações e calibrações foram realizadas à temperatura de $23,0{ }^{\circ} \mathrm{C}$, desaeradas com $\mathrm{N}_{2}$ comercial saturado com água por 10 min e mantidas sob esta atmosfera inerte durante as
Tabela 1. Resultados das determinações de umidade (porcentagem) nas amostras de sedimento das represas e reservatórios do Rio Tietê e a relação entre a massa de sedimento úmido trabalhado nas titulações complexométricas com a massa seca

\begin{tabular}{lcccc}
\hline \multirow{2}{*}{ Ambiente } & & & \multicolumn{2}{c}{ Sedimento $(\mathrm{mg})$} \\
\hline Rasgão & Perfil $(\mathrm{cm})$ & Umidade $(\%)$ & Úmido & Seco \\
\hline \multirow{2}{*}{ Billings } & $0-5$ & 89,17 & 2800 & 303,2 \\
& $5-10$ & 85,67 & 2100 & 300,9 \\
Barra Bonita & $0-5$ & 88,84 & 2700 & 301,3 \\
& $5-10$ & 84,41 & 2000 & 311,8 \\
Bariri & $0-5$ & 58,64 & 730,0 & 301,9 \\
& $5-10$ & 47,66 & 580,0 & 303,6 \\
Promissão & $0-5$ & 82,19 & 1700 & 302,8 \\
& $5-10$ & 76,71 & 1300 & 302,8 \\
& $0-5$ & 81,27 & 1600 & 299,7 \\
& $5-10$ & 64,00 & 850,0 & 306,0 \\
\hline
\end{tabular}

titulações. Os incrementos de titulante (padrão de cádmio ou cobre preparado nas mesmas condições que amostra) variaram de $80 \mu \mathrm{L}$ no início da titulação até $1,08 \mathrm{~mL}$ no seu final, através de uma microbureta de pistão (Gilmont GS 2000) que permite precisão de $\pm 0,2 \mu \mathrm{L}$ em $50,0 \mathrm{~mL}$ de solução ou suspensão.

A padronização das soluções-estoque de concentração de 0,2170 e $0,2217 \mathrm{~mol} \mathrm{~L}{ }^{-1}$ de cádmio $\left(\mathrm{CdNO}_{3} \cdot 4 \mathrm{H}_{2} \mathrm{O}\right.$, Merck) e cobre $\left(\mathrm{CuNO}_{3} .3 \mathrm{H}_{2} \mathrm{O}\right.$, Merck), respectivamente, foi realizada segundo o manual Orion ${ }^{22,43}$. Para o acondicionamento destas, o pH foi mantido em torno de 4 para evitar hidrólise e foram guardadas na geladeira.

O potencial redox foi monitorado através de um potenciômetro Micronal B375 A e o potencial hidrogeniônico através de um Fento $420 \mathrm{p}$, ambos com precisão de $0,01 \mathrm{mV}$ ou 0,01 unidades de $\mathrm{pH}$, respectivamente. Para as medidas de $\mathrm{pH}$ foi utilizado um eletrodo de vidro combinado, saturado com $\mathrm{KCl}$, da Ingold. Foram tomados 13 pontos para cada titulação, bem como para as curvas de calibração, que foram obtidas titulando-se uma solução de $\mathrm{NaNO}_{3}$ $1,0 \mathrm{~mol} \mathrm{~L}^{-1}, \mathrm{pH} 6,00 \pm 0,05$ (PIPES 7,5 x 10-3 $\mathrm{mol} \mathrm{L}^{-1}$ ) com o íon metálico de interesse.

As determinações de metal livre foram realizadas utilizandose um eletrodo de dupla junção de $\mathrm{Ag} / \mathrm{AgCl}$, saturado com $\mathrm{KNO}_{3}$ (Orion 90-02) como referência e os eletrodos de membrana sólida sensível a íons $\mathrm{Cd}^{2+}$ (Orion 9448) e $\mathrm{Cu}^{2+}$ (Orion 9429). Os potenciais foram anotados após a estabilização das medidas, o que requereu de 5 a 10 min no início da titulação e menos de 1 min na fase final. Somente para as determinações de cádmio adicionaram-se 20,0 mg de CdS, a fim de que o potencial redox atingisse o equilíbrio mais rapidamente, já que este sal não afetaria o objetivo desta análise por ser extremamente estável.

As curvas analíticas foram realizadas em triplicatas feitas com eletrólito de fundo, enquanto que para as amostras dos ambientes de estudo foram realizadas duplicatas, escolhidas de forma aleatória.

\section{RESULTADOS E DISCUSSÃO}

Lemes, Figueiredo Filho e Pires ${ }^{44}$ em uma pesquisa sobre a influência da mineralogia dos sedimentos das bacias hidrográficas dos rios Mogi-Guaçu e Pardo na composição química das águas de abastecimento público citam que a mobilização de metais pesados a partir do material suspenso e dos sedimentos de fundo é potencialmente perigosa, não somente para o ecossistema, mas também para o suprimento de água potável. Segundo os pesquisadores, a mobilização é principalmente causada por quatro tipos de mudanças químicas na água: elevada concentração salina; mudanças da 
condição redox, geralmente associada à diminuição do potencial de oxigênio devido à eutrofização, queda do $\mathrm{pH}$ e aumento do uso de agentes naturais e sintéticos. Além deste processo pelo qual os contaminantes inorgânicos são disponibilizados do sedimento para a coluna d'água, para os animais ou as plantas, existem, também, outros processos de transformação por processos bioquímicos.

Calmano, Hong e Forstner ${ }^{14}$ realizaram monitoramento de $\mathrm{pH}$ e potencial redox em um sedimento do porto de Hamburgo, Alemanha, variando o estado de oxidação do mesmo para verificar a retenção e a biodisponibilidade de $\mathrm{Zn}, \mathrm{Pb}, \mathrm{Cu}$ e $\mathrm{Cd}$ nas frações dissolvida e particulada. Na fração particulada o grupo realizou uma extração seqüencial para determinar a fase específica das formas de ligação do metal. Eles concluíram que há uma maior mobilização de $\mathrm{Cd}$ e $\mathrm{Zn}$ em relação a $\mathrm{Cu}$ e $\mathrm{Pb}$ para a fase solúvel ao final dos estágios redox e isto se deve, preferencialmente, à maior estabilidade de $\mathrm{Cu}$ e $\mathrm{Pb}$ na fase orgânica/sulfídrica.

Assim, na investigação da competição entre os fenômenos de complexação e adsorção em um sistema aquático, é necessário que o pH (e a força iônica) seja mantido constante ${ }^{22}$ para que se tenha uma mobilidade catiônica "quase constante" 14 e redução de pares iônicos e precipitados decorrentes de uma hidrólise.

As medidas potenciométricas ocorreram em temperatura $\left(\approx 23^{\circ} \mathrm{C}\right)$, força iônica $\left(\mathrm{NaNO}_{3} 1,0 \mathrm{~mol} \mathrm{~L}-1\right)$ e pH (PIPES, pH 6,00 \pm 0,05) constantes. Sob estas condições, garante-se que todo o íon metálico está na forma livre, pois não há deslocamento do equilíbrio pela temperatura e não há a formação de pares iônicos ou de produtos da hidrólise devido ao efeito da força iônica e do controle do $\mathrm{pH}$, respectivamente.

A seleção do tampão PIPES baseou-se nos estudos de $\mathrm{Silva}^{22}$, que discutiu a afinidade de quatro tampãos (PIPES, HEPES, BES, MES) pelos íons cobre(II) comparando-os com uma solução guia. Nesta solução guia (a autora não informou o meio de preparação) supõe-se que todos os íons cobre(II) estejam na forma iônica e que um afastamento da curva de titulação significa que uma fração do íon cobre(II) total foi complexada, adsorvida ou sofreu hidrólise pelo tampão. A autora concluiu que o tampão PIPES foi o que apresentou menor afinidade pelo íon cobre, devido à quase superposição sobre a curva guia.

Para a construção da curva analítica de calibração, a concentração de metal livre $[\mathrm{M}]_{\mathrm{L}}$ é considerada como sendo igual à sua concentração total, $[\mathrm{M}]_{\mathrm{T}}$, que é calculada para cada ponto da titulação através da relação:

$[\mathrm{M}]_{\mathrm{L}}=[\mathrm{M}]_{\mathrm{T}}=\mathrm{V} * \mathrm{C}_{\mathrm{M}} /\left(\mathrm{V}_{0}+\mathrm{V}\right)$

onde $\mathrm{V}$ e $\mathrm{C}_{\mathrm{M}}$ são, respectivamente, o volume e a concentração da solução titulante adicionada na cela de titulação, $V_{0}$ é o volume inicial da solução aquosa (tampão e força iônica) titulada. A partir do gráfico de $\mathrm{E}$ (potencial medido) em função de $\log [\mathrm{M}]_{\mathrm{T}}$, obtémse os parâmetros $\mathrm{E}^{0^{\prime}}$ (potencial condicional) e $\mathrm{S}$ (coeficiente angular) da Equação de Nernst, que serão utilizados para a determinação de metal livre ao longo da titulação das amostras de suspensão e da fração dissolvida.

Os dados das titulações potenciométricas foram convertidos, portanto, de milivolts para concentração de cádmio(II) ou cobre (II) $\left(\left[\mathrm{Cd}^{2+}\right]\right.$ ou $\left.\left[\mathrm{Cu}^{2+}\right]\right)$ pelo uso da Equação de Nernst:

$\mathrm{E}=(-77,5 \pm 6,7)+(28,0 \pm 1,5) \times \log \left[\mathrm{Cd}^{2+}\right]$

$\left.\mathrm{E}=(189 \pm 0,7)+(28,7 \pm 0,34) \times \log \left[\mathrm{Cu}^{2+}\right]\right)$

apresentando um comportamento nernstiano (valores dos coeficientes angulares entre 27,5 e $30,0 \mathrm{mV}$, para $\mathrm{n}=2$ da Equação de $\mathrm{Nernst}^{45}$ ) cuja concentração mínima na região linear foi de 9,56 $\mu \mathrm{mol} \mathrm{L}{ }^{-1}$, para cádmio e $11,80 \mu \mathrm{mol} \mathrm{L}^{-1}$, para cobre (Figura 2a).

As titulações potenciométricas para cádmio e cobre revelaram que ambos (a fase dissolvida e os sedimentos) são capazes de complexar e adsorver os respectivos íons. A Figura 2 apresenta as curvas de titulação para a fase dissolvida (Figura 2b) e sedimento úmido (Figura 2c) junto com o eletrólito de fundo (Figura 2a). O gráfico de Scatchard apresentou dois segmentos de reta referentes às duas classes de sítios de complexação para todos os ambientes em ambos os metais e, portanto, sua análise revela que para cada metal pelo menos dois ligantes têm concentrações e constantes de estabilidade distintas; sendo que a maior estabilidade está associada aos ligantes que possuem menores concentrações.
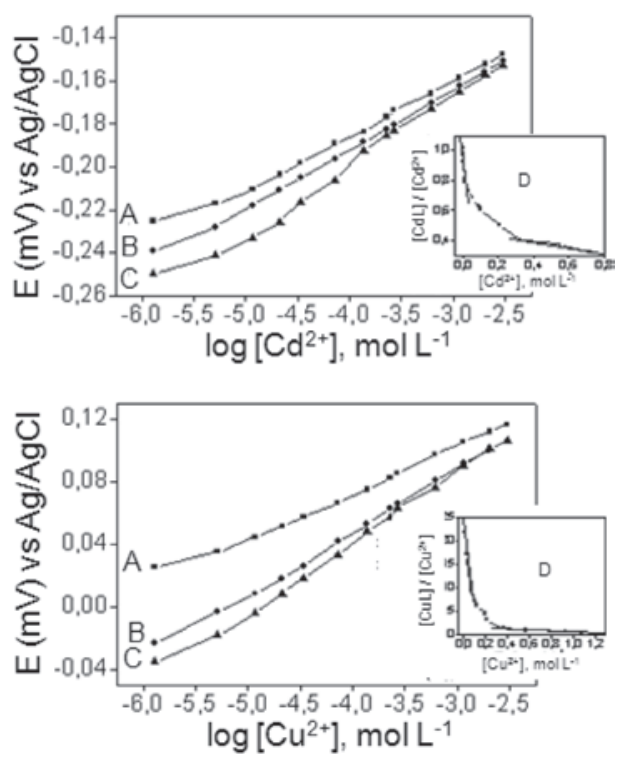

Figura 2. (a) Curva de titulação de 50,0 $\mathrm{mL}$ de solução de $\mathrm{NaNO}_{3} 1,0 \mathrm{~mol}$ $L^{-1}$ e pH = 6,00 (PIPES 7,5 $\left.\times 10^{-3} \mathrm{~mol} \mathrm{~L}^{-1}\right)$ com solução estoque de $\mathrm{Cd}^{2+}$ ou $\mathrm{Cu}^{2+}$; (b) curva de titulação da fração dissolvida (filtrado) do sedimento do reservatório Billings nas mesmas condições de força iônica e pH citadas no item (a); (c) curva de titulação do sedimento úmido nas mesmas condições de força iônica e pH citadas no item (a); (d) gráfico de Scatchard para a complexação de $\mathrm{Cd}^{2+}$ e $\mathrm{Cu}^{2+}$ com a fração dissolvida. Notar que as duas linhas sugerem a existência de dois sítios de ligação

Os parâmetros de complexação obtidos estão listados na Tabela 2 , onde também se encontram os resultados de outras variáveis ambientais analisadas: granulometria, carbono orgânico total (TOC), sulfeto volatilizável por acidificação (SVA), $\mathrm{pH}$ e $\mathrm{E}_{\mathrm{H}}$. Os resultados numéricos foram dispostos na forma de uma matriz de ordem 10x29, na qual estão representadas as 10 determinações realizadas e as 29 variáveis avaliadas, a fim de se realizar uma análise exploratória ou multivariada, utilizando-se a ferramenta estatística MATLAB $6.1^{46}$.

Uma análise prévia da Tabela 2 nas colunas 10 a 29 revelou que a adsorção de cádmio e cobre é predominante em todos os ambientes e que os sítios de adsorção de classe 1 são os mais estáveis e importantes no controle da concentração destes íons no sedimento $\left({ }^{1} \mathrm{KA}>{ }^{2} \mathrm{KA} \mathrm{e}{ }^{1} \mathrm{CA}>^{2} \mathrm{CA}\right.$ ) em relação à complexação (fase dissolvida).

Segundo Abate e Masini ${ }^{16}$, os sítios de maior afinidade pelo cátion metálico são titulados primeiro, o que resulta em um segmento linear de maior inclinação (maior ${ }^{\mathrm{j}} \mathrm{K}$ ). Entretanto, estes são rapidamente ocupados e, assim, os sítios de menor afinidade passam a reger o processo, resultando em uma mudança gradual de inclinação até que nova porção linear seja definida, com inclinação menor que a primeira. Neste contexto, a capacidade de complexação (CC) para os íons $\mathrm{Cu}^{2+}$ e $\mathrm{Cd}^{2+}$ nos ambientes Rasgão, Billings, Bariri e Promissão os sítios de classe 2 foram os mais importantes no controle da concentração de íons livre em solução 
Tabela 2. Resultados das análises em sedimento de $\mathrm{pH}, \mathrm{E}_{\mathrm{H}}$, granulometria, sulfeto volatilizável por acidificação (SVA), carbono orgânico total (TOC), concentração basal de cádmio e cobre, constante de formação condicional $\left(\log { }^{j} \mathrm{~K}\right)$ para complexação $\left(\log { }^{j} \mathrm{~K}_{\mathrm{C}}\right)$ e adsorção $(\log$ ${ }^{\mathrm{j}} \mathrm{K}_{\mathrm{A}}$ ) e capacidade de complexação $\left({ }^{\mathrm{i}} \mathrm{CC}\right)$ e adsorção $\left({ }^{\mathrm{i}} \mathrm{CA}\right)$ para o ligante $1\left({ }^{1} \mathrm{CC}\right.$ ou ${ }^{1} \mathrm{CA}$ ), para o ligante $2\left({ }^{2} \mathrm{CC}\right.$ ou $\left.{ }^{2} \mathrm{CA}\right)$ e total $\left({ }^{\mathrm{T}} \mathrm{CC}\right.$ ou $\left.{ }^{\mathrm{T}} \mathrm{CA}\right)$ calculado a partir de titulações do sedimento com íons $\mathrm{Cd}^{2+}$ e $\mathrm{Cu}^{2+}$ em pH 6,00 $\pm 0,05$ e força iônica de $1,0 \mathrm{~mol} \mathrm{~L}^{-1}\left(\mathrm{NaNO}_{3}\right)$

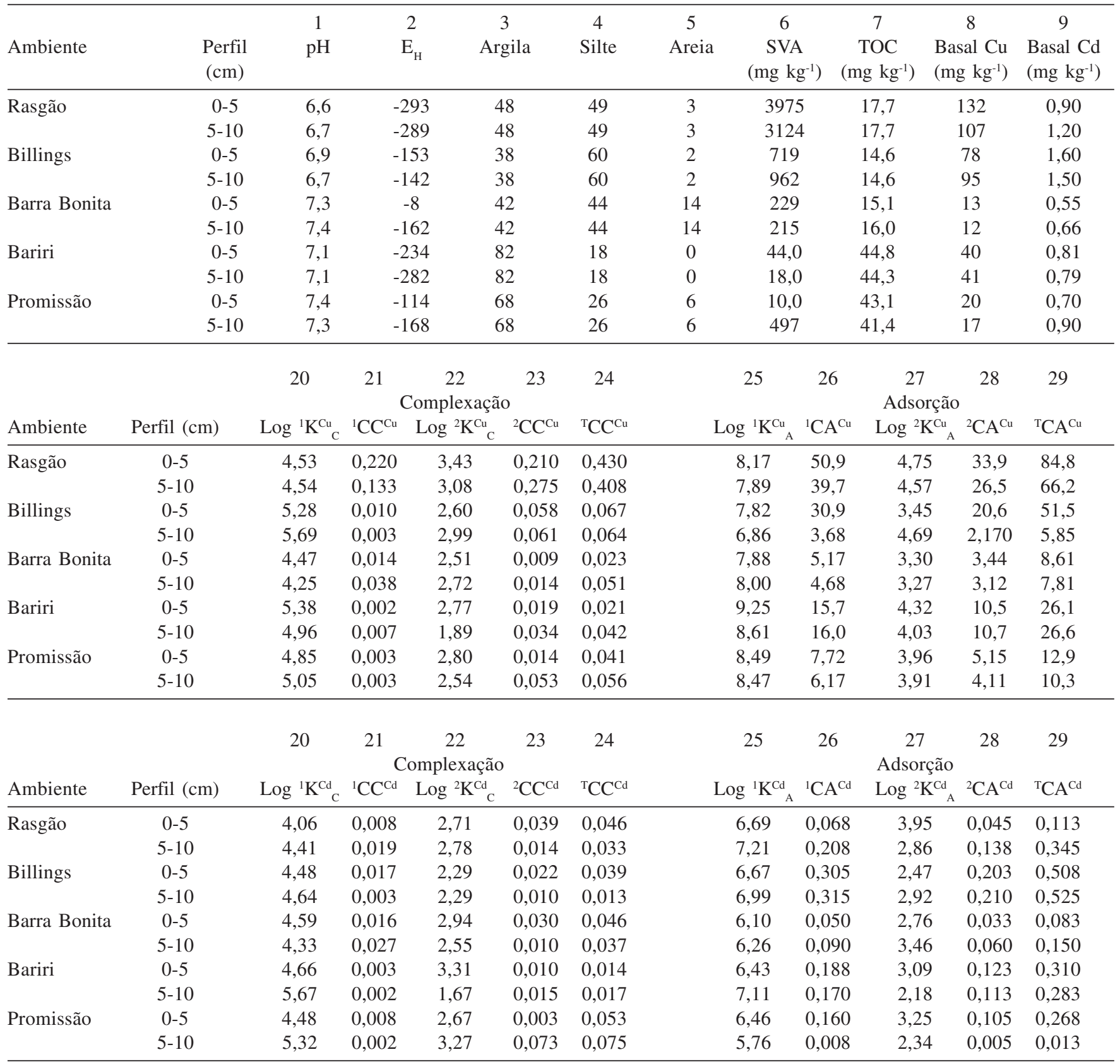

CC: $\mathrm{mmol} \mathrm{L}^{-1}$; CA: mmol g-1

$\left({ }^{1} \mathrm{CC}<{ }^{2} \mathrm{CC}\right.$ e $\left.{ }^{1} \mathrm{~K}>{ }^{2} \mathrm{~K}\right)$, pois apesar dos sítios de classe 1 apresentarem maior estabilidade (maior ${ }^{1} \mathrm{~K}$ ), sua ${ }^{1} \mathrm{CC}$ é baixa. Entretanto, estes sítios tiveram maior significância no controle de $\mathrm{Cu}^{2+}$ e $\mathrm{Cd}^{2+}$ para Barra Bonita.

O programa MATLAB $6.1^{46}$ calculou os scores (ambientes), loadins (variáveis) e fez a representação gráfica dos principais componentes, permitindo a caracterização dos ambientes em relação à sua capacidade de complexação e adsorção e às demais variáveis.

Todos os valores foram auto-escalados a fim de remover os efeitos das diferentes escalas e unidades das medidas e transformálos em concordância com os pressupostos do sistema de análise de componentes principais (PCA) ${ }^{27,28,47-49}$.
O modelo classificou satisfatoriamente as 10 amostras em 5 classes distintas utilizando-se três componentes principais cuja variância explicada foi de $76,67 \%$ (Figura $3 a$ - scores e $3 b$ - loadings), onde PC1 (37,46\% da variância total) separa as amostras Rasgão e Billings (ambientes mais impactados) das demais, PC2 (22,01\% da variância total) separa as amostras de Barra Bonita e PC3 (17,20\% da variância total) distingue as profundidades de coleta das amostras de Rasgão, Billings e Bariri, sendo os maiores valores de PC3 encontrados nas amostras de profundidade de $0-5 \mathrm{~cm}$. As amostras de Barra Bonita possuem comportamento muito semelhante quanto à profundidade $\mathrm{e}$ não são distinguidas pela PC3 e as amostras de Promissão possuem comportamento inverso das demais (ambiente menos impactado). 

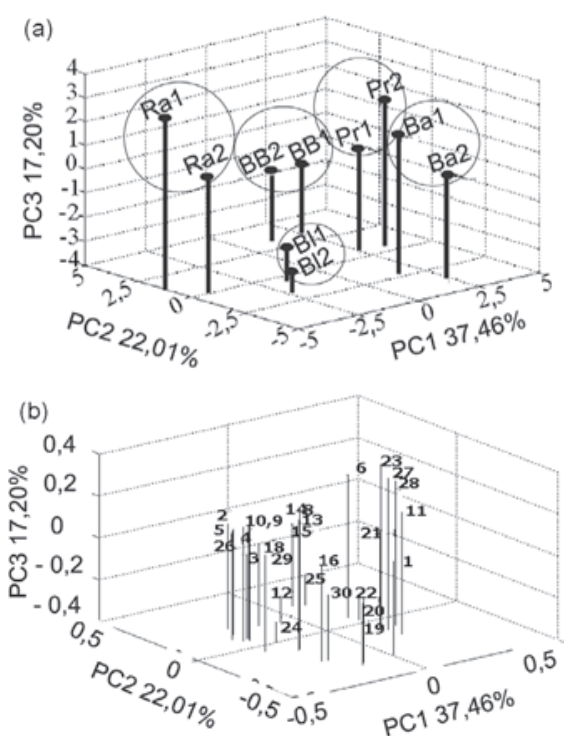

Figura 3. Análise de componentes principais. Gráficos de (a) scores e (b) loadings

De acordo com a PCA, pode-se observar que a CC e a CA, tanto para cádmio quanto para cobre (apesar de cobre ter merecido maior importância) nos ambientes Billings e Rasgão são influenciadas pelo alto conteúdo de silte e SVA e menores valores de $\mathrm{E}_{\mathrm{H}} \mathrm{e}$ $\mathrm{pH}$, caracterizando os ambientes como anóxidos e com alto potencial em complexar ou adsorver. Estes resultados estão de acordo com os dados encontrados na literatura. Ashley ${ }^{23}$ em um estudo sobre as diferenças de adsorção entre $\mathrm{Cu}$ e $\mathrm{Zn}$ em ácidos húmicos confirmou a ordem de estabilidade de complexos sulfídricos: $\mathrm{Cu}(\mathrm{II})>\mathrm{Zn}$ (II) $>\mathrm{Cd}$ (II). Calmano, Hong e Förstner ${ }^{14}$ relataram a mobilização de $\mathrm{Cd}$ e $\mathrm{Cu}$ de sedimentos anóxidos $(\mathrm{pH}=6,43)$ quando variaram os ciclos oxidativos e encontraram que quanto menor o pH maior é mobilização destes metais, principalmente do sedimento oxidado e que para $\mathrm{Cd}$ houve uma maior liberação deste metal de todas as fase extraídas para a fração solúvel; ao contrário para $\mathrm{Cu}$ que durante o ciclo oxidativo a porcentagem na fração moderadamente reduzida aumentava enquanto a orgânica/sulfídrica diminuía lentamente. Fernandes ${ }^{50}$ em um estudo sobre a distribuição de metais em sedimentos cita que $\mathrm{Cu}$ está, na maioria das vezes, ligado à fração orgânica/sulfídrica (70-80\%) em ambientes altamente poluídos.

Pela PC1 estes dois ambientes foram separados dos demais devido, principalmente, aos maiores teores basais de $\mathrm{Cd}$ e $\mathrm{Cu}$, parâmetros estes acentuados pelo fato da Região Metropolitana de São Paulo ser uma das áreas de maior adensamento urbano do mundo, caracterizando assim, segundo Silvério ${ }^{39}$, o nível trófico destes ambientes como de contaminação alta.

Os reservatórios de Barra Bonita e Promissão são caracterizados pelos altos conteúdos de areia (e argila para Promissão) e altos valores de $\mathrm{E}_{\mathrm{H}}$ e $\mathrm{pH}$. Bariri possui elevado conteúdo de argila e teor de carbono orgânico.

Os estudos de Patrick e Verloo ${ }^{51}$ relatam que as condições de $\mathrm{pH}$ e $\mathrm{E}_{\mathrm{H}}$ afetam significativamente as espécies de metais e metalóides presentes em um ambiente aquático, condicionando-as a um tipo de ligante ou à forma livre. Dentro do espectro do tamanho das partículas, Novotny ${ }^{52}$ argumenta que a argila e as partículas orgânicas possuem alta capacidade de sorção para muitos compostos e atuam como transportadores intermediários de contaminantes em ambientes aquáticos. Segundo Sodré et al. ${ }^{53}$, na matéria orgânica estes sítios de ligação podem ser, principalmente, unidades funcionais carboxílicas e fenólicas e nos argilominerais expansivos (periferias de argilas silicatadas 2:1) os grupos funcionais podem ocorrer nos espaços entre as camadas octaédricas presentes em suas estruturas cristalinas. Calmano et al. ${ }^{14}$ e Neubecker e Allen ${ }^{54}$ citam outras formas de ligação, tais como carbonatos, sulfetos, fosfatos também presentes em grandes quantidades em tais ambientes.

Assim, Bariri e Promissão poderão ter os seus ambientes tão contaminados quanto Billings e Rasgão pelas atividades antrópicas desenvolvidas na bacia hidrográfica, já que o primeiro recebe a influência não somente do Rio Tietê, mas de outro tributário, o rio Jaú, situado a montante da represa de Bariri, que tem um papel significativo na questão de uso e ocupação dos solos ${ }^{55}$.

A PC2 caracterizou o ambiente de Barra Bonita devido à sua menor estabilidade em complexar ou adsorver os metais cádmio e cobre em relação aos demais ambientes, devido à pouca presença de substâncias potencialmente complexantes e ao alto teor de areia, apesar de Leite $^{56}$ citar que a maior parte dos ligantes presentes encontrados nestes sistemas aquáticos são bases fracas de Lewis que formam moléculas similares às dos organismos vivos.

Os resultados obtidos pela PCA são semelhantes aos obtidos pela HCA (Figura 4), ambos são satisfatórios, pois também mostraram que é possível classificar as amostras em classes distintas. De acordo com a Figura 4 observa-se que existe uma distinção entre dois grupos principais: Billings e Rasgão formando um agrupamento e os outros ambientes formando um outro, o que é esperado, uma vez que estes ambientes são menos impactados.

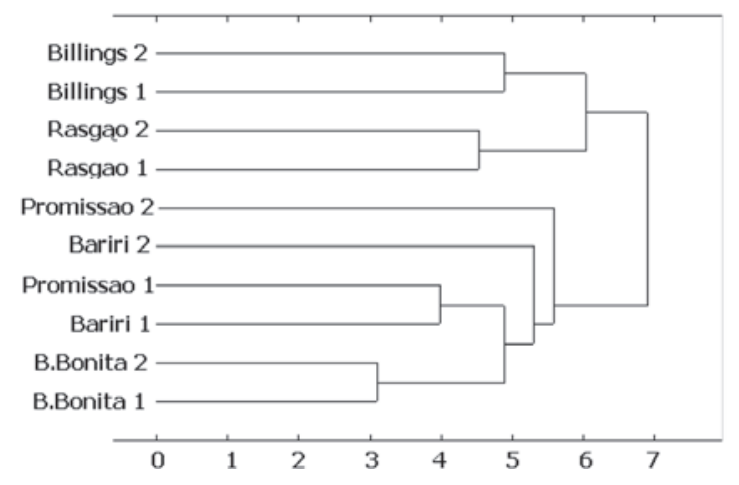

Figura 4. Dendograma obtido na análise hierárquica de agrupamento

\section{CONCLUSÃO}

Os fenômenos de acúmulo de xenobióticos nos sedimentos os qualificam como de extrema importância em estudos de impacto ambiental, pois registram em caráter mais permanente os efeitos de contaminação. A associação destas espécies a partículas sólidas, assim como a vários agentes complexantes, pode alterar a especiação química do metal, influenciando sua distribuição, seus mecanismos de transporte e destino, além da sua biodisponibilidade.

Os sedimentos naturais do reservatório Billings e das usinas hidrelétricas Rasgão, Barra Bonita, Bariri e Promissão, de acordo com os resultados obtidos, funcionam como barreiras efetivas na fixação dos elementos estudados. A boa afinidade apresentada pelos sedimentos indica a possibilidade do seu uso na fixação de metais em ambientes contaminados. No caso de cobre, sua alta estabilidade de complexação diminui seu potencial tóxico. No que se refere ao cádmio, os sistemas apresentam uma situação mais crítica, já próxima da saturação, fato este que se deve não apenas à natureza dos ligantes, mas também à pouca afinidade do metal pelos sítios de ligação. Empregando-se os métodos exploratórios PCA e HCA foi possível correlacionar as diferentes variáveis ambientais com a procedência de cada ambiente natural do Rio Tietê. 


\section{AGRADECIMENTOS}

À bolsa concedida pela CAPES e à FAPESP (98/12177- 0) pelo suporte financeiro. Agradeço ao querido Prof. Dr. E. F. A. Neves, que veio a falecer em 2006, dono de um respeito, carinho e amabilidade tão vastos e profundos quanto o seu conhecimento.

\section{REFERÊNCIAS}

1. Tundisi, J. G.; Matsumura-Tundisi, T.; Henry, R.; Rocha, O.; Hino, K. Em Limnologia e Manejo de Represas; Tundisi, J. G., ed.; EDUSP: São Paulo, Série: Monografia em Limnologia, 1988, vol. 1, tomo1.

2. Straskraba, M.; Tundisi, J. G.; Reservoir Water Quality Management, ${ }^{\text {st }}$ ed., ILEC- Scientific Publ. Japan: Otsu, 1999, vol. 9.

3. Tundisi, J. G.; Matsumura-Tundisi, T.; Arch. Hydrobiol. Beih. Ergebn. Limnol. 1990, 33, 661.

4. Mozeto, A. A.; Silvério, P. F.; DePaula, F. C. F.; Bevilacqua, J. E.; Patella, E.; Jardim, W. F. Em Sediment quality and management: insight and progress; Munauwar, M., ed.; Ecovision World Monograph Series, Canadá, 2003, p. 221

5. CETESB - Companhia Estadual de Tecnologia e Saneamento Básico do Estado de São Paulo.; Relatório de qualidade de águas interiores do Estado de São Paulo; Série Relatórios: São Paulo, 2000.

6. Manahan, S. E.; Fundamentals of Environmental Chemistry, Lewis Publishers: New York, 1993.

7. Blasco, J.; Sáenz, V.; Gómez-Parra, A.; Sci. Total Environ. 2000, 24, 189.

8. Caille, N.; Tiffreau, C.; Leyval, C.; Morel, J. L.; Sci. Total Environ. 2003, 301, 239.

9. Xue, H.; Sigg, G. L.; Anal. Chim. Acta 1998, 363, 249.

10. Baudrimont, M.; Schäfer, J.; Marie, V.; Maury-Brachet, R.; Bossy, C.; Boudou, A.; Blanc, G.; Sci. Total Environ. 2005, 337, 265.

11. Gargioni, V.; Dissertação de Mestrado, Universidade Estadual de Campinas, Brasil, 1991.

12. Müller, B.; Duffek, A.; Aquat. Geochem. 2001, 7, 107.

13. Charlatchka, R.; Cambier, P.; Water, Air, Soil Pollut. 2000, 118, 143.

14. Calmano, W.; Hong, J.; Förstner, U.; Water Sci. Technol. 1993, 28, 223.

15. Lombardi, A. T.; Vieira, A. A. H.; Phycologia 1998, 37, 34.

16. Abate, G.; Masini, J. C.; Quim. Nova 1999, 22, 661.

17. Abate, G.; Masini, J. C.; J. Braz. Chem. Soc. 2001, 12, 109

18. Pinheiro, J. P.; Mota, A. M.; Gonçalves, M. L. S.; Weidje, M. van der; Leeuwen, H. P.; J. Electroanal. Chem. 1996, 410, 61.

19. Xue, H.; Sunda, W. G.; Environ. Sci. Technol. 1997, 31, 1902.

20. Parmeggiani, A. C.; Masini, J. C.; J. Braz. Chem. Soc. 2003, 14, 416.

21. Rozan, T. F.; Benoit, G.; Marsh, H.; Chin, Y-P.; Environ. Sci. Technol. 1999, 33, 1766.

22. Silva, S. T.; Dissertação de Mestrado, Universidade de Campinas, Brasil, 1996

23. Ashley, J. T. F.; Chemosphere 1996, 33, 2175.

24. Castro, G. R.; Padilha, C. C. F.; Rocha, J. C.; Valente, J. P. S.; Florentino, A. O.; Eclética Química 2005, 30, 45.

25. Corti, G. S.; Botaro, V. R.; Gil, R. P. F.; Gil, L. F.; Polímeros 2004, 14, 313.
26. Neubecker, T. A.; Allen, H. E.; Water Res. 1983, 17, 1.

27. Ferreira, E. C.; Rodrigues, S. H. B. G.; Ferreira, M. M. C.; Nóbrega, J. A.; Nogueira, A. R. A.; Eclética Química 2002, 27, 77.

28. Silva, F. V.; Kamogawa, M. Y.; Ferreira, M. M. C.; Nóbrega, J. A.; Nogueira, A. R. A.; Eclética Química 2002, 27, 91.

29. Latini, R. M.; Bellido Jr., A. V.; Vasconcellos, M. B. A.; Dias Jr., O. F.; Quim. Nova 2001, 24, 724.

30. Oliveira, A. P.; Gomes Neto, J. A.; Ferreira, M. M. C.; Eclética Química 2006, $31,7$.

31. Parisotto, G.; Souza, J. S.; Ferrao, M. F.; Furtado, J. C.; Molz, R. F.; Rev. Bras. Cienc. Farm. 2005, 41, 499.

32. http:// www.ambientebrasil.com.br, acessada em Janeiro 2006.

33. http://www.rededasaguas.org.br/nucleo/na_hidrografia, acessada em Janeiro 2006.

34. CETESB, Relatório de qualidade de águas interiores do Estado de São Paulo, Série Relatórios: São Paulo, 1994.

35. Ambuhl, H.; Buhrer, H.; Schwieiz. Z. Hydrol. 1975, 37, 175.

36. ABNT - Associação Brasileira de Normas Técnicas; Rochas e solos. NBR 6502/95, Rio de Janeiro, 1995.

37. De Paula, F. C. F.; Appl. Geochem. 2001, 16, 1139.

38. Allen, H. E.; Fu, G.; Deng, B.; Environ. Toxicol. Chem. 1993, 12, 1441

39. Silvério, P. F.; Dissertação de Mestrado, Universidade Federal de São Carlos, Brasil, 2000

40. Mozeto, A. A.; Pistolato, M. L.; Nóbrega, J. A.; Krushe, A. V.; V Encontro Nacional de Química Analítica, Salvador, Brasil, 1989.

41. Neves, E. F. A.; Benedetti-Filho, E.; Javaroni, R. C. A.; Humic Substances $3^{\text {rd }}$ International Colloquium on Process Related Environmental Analytical Chemistry, Leipzig, Alemanha, 2000.

42. Water Analysis; Instructional Manual: Orion Copper Electrode, Thermo Electron Corporation: Beverly, 1995.

43. Water Analysis; Instructional Manual: Orion Cadmium Electrode, Thermo Electron Corporation: Beverly, 1995

44. Lemes, M. J. L.; Figueiredo Filho, P. M.; Pires, M. A. F.; Quím. Nova, 2003, 26,13 .

45. Dias, I. L. T.; Oliveira Neto, G.; Martins, L. S.; Lecta 2004, 22, 11

46. MATLAB. Version 6.1; Program for Chemometric, Natick: The MathWorks, 1997.

47. Tokalioglu, S.; Kartal, S.; Gunes, A. A.; Int. J. Environ. Anal. Chem. 2004, 84,691

48. Beebe, K. R.; Pell, R. J.; Seasholt, M. B.; Chemometrics: a practical guide, John Wiley \& Sons: New York, 1998

49. Hannon, J. A.; Wilkinson, M. G.; Delahunty, C. M.; Wallace, J. M.; Morrissey, P. A.; Beresford, T. P.; Int. Dairy J. 2005, 15, 263.

50. Fernandes, H. R. S. M.; Environ. Sci. Pollut. Res. 1997, 39, 69.

51. Patrick, W. H. Jr.; Verloo, M.; Water Sci. Technol. 1998, 37, 165.

52. Novotny, V. Em Heavy metals: problems and solutions; Salomons, W.; Forstner, U.; Mader, P., eds.; Springer: Berlin, 1995.

53. Sodré, F. F.; Lenzi, E.; Costa, A. C. S.; Quim. Nova 2001, 24, 324.

54. Neubecker, T. A.; Allen, H. E.; Water Res. 1993, 17, 1.

55. Souza, A. D. G.; Tundisi, J. G.; Rev. Bras. Biol. 2000, 60, 563.

56. Leite, M. A.; Tese de Doutorado, Universidade Federal de São Paulo, Brasil, 2002 . 